\title{
Life Cycle Assessment of Hydrogel Used in Hydroponics for the Impatiens New Guinea Production
}

\author{
Silvia Paola Venegas Segura1, Martha Lilia Domínguez Patiño',2, Miguel Aguilar Cortes ${ }^{1,2}$, \\ Jorge Avelino Domínguez Patiño ${ }^{1,2}$, Luz Elva Marín Vaca1,2, Nadia Lara Ruiz ${ }^{1,2}$, \\ Rosa María Melgoza Alemán ${ }^{1}, 0$ oscar Gabriel Villegas Torres ${ }^{3}$ \\ ${ }^{1}$ Facultad de Ciencias Químicas e Ingeniería, Universidad Autónoma del Estado de Morelos, Cuernavaca, \\ México \\ ${ }^{2}$ Centro de Investigación en Ingeniería y Ciencias Aplicadas, Universidad Autónoma del Estado de Morelos, \\ Cuernavaca, México \\ ${ }^{3}$ Facultad de Ciencias Agropecuarias, Universidad Autónoma del Estado de Morelos, \\ Cuernavaca, México \\ Email:maguilarc@uaem.mx
}

Received 16 April 2016; accepted 16 May 2016; published 19 May 2016

Copyright (C) 2016 by authors and Scientific Research Publishing Inc.

This work is licensed under the Creative Commons Attribution International License (CC BY). http://creativecommons.org/licenses/by/4.0/

(c) (i) Open Access

\section{Abstract}

The environmental impact on the planet leads to the search of new processes that are friendly with the environment and obtaining high quality products. In this sense, green chemistry is used in the generation of products through processes that do not affect the planet. In many of these processes and in general, the use of water has been depleted this resource of vital importance for the survival of living things. In Mexico, $77 \%$ of water is used in agriculture; $14 \%$ in the public supply; $5 \%$ in the thermoelectric plants and $4 \%$ in the industry. In research presented, hydroponics is essential in the process and is defined as a technique used to reduce excessive water consumption, by providing the necessary nutrients, in addition to preventing soil erosion by allowing the growth of plants without use of ground. The potassium polyacrylate is a super-absorbent polymer (Hydrogel) capable of absorbing water up to 500 times of its weight and has a life span of 10 years. When mixed with a substrate, the required nutrient solution potassium polyacrylate allows to lengthen the interval watering and thus reducing the consumption of water from plants. Morelos is the largest producer of ornamental plants in the country, due to its privileged climate and location. In the present work using the hydroponic methodology, we planted cuttings of Bethlehem New Guinea (Impatiens New Guinea) in a substrate made by $60 \%$ of coconut fiber, $20 \%$ tepojal, $20 \%$ ground sheet mixed with polymer of potassium $(20 \mathrm{~g}$ per litre), $400 \mathrm{ml}$ of Steiner nutrient solution in concentrations of $40 \%, 60 \%, 80 \%$ and $100 \%$, varying the interval of $3-, 6-, 8-$ and 10-day watering. The variables considered are: concentration of chlorophyll, the plant height, leaf 
area, number of stems and weight dry total. The 12 principles of green chemistry applied to hydroponics using polyacrylate of potassium as part of the substrate in Bethlehem New Guinea (Impatiens New Guinea) to determine the analysis of life cycle (LCA), doing the balance of inputs and outputs of the system, and the stages of the LCA. Finally the SimaPro software was used to measure the environmental impact of the use of the polymer in hydroponics by varying the watering interval and the concentration of the Steiner solution, entering data for the concentration of Steiner, and the volume of water used. With the results obtained by measurement of weight dry total and concentration of Steiner solution and using the Software SimaPro, Steiner saw that the solution with the concentration of $60 \%$ using potassium polyacrylate as part of the hydroponic substrate in Bethlehem New Guinea and in the range of 10 days to water generated less environmental impact. On the other hand, in the same figure, it is determined that the Steiner solutions with concentrations of 80 and $100 \%$ generate a bigger environmental impact, due to the saturation of the solutions.

\section{Keywords}

Steiner Solution, Environmental Impact, SimaPro

\section{Introduction}

Green chemistry is responsible for finding sustainable processes to reduce the environmental impact. An analysis to quantify the environmental impact generated by a product or service is the life-cycle analysis (LCA). LCA measures the damage of a product generated from the beginning of life until death. Green chemistry tries to have very green processes, a stroke can help to improve these processes and reduce the damage that generates from each process.

The activities or processes, because environmental impacts represent consumption of resources, emit substances into the environment and generate other environmental changes during its life.

Life cycle analysis is a methodological framework to estimate and assess the environmental impacts attributable to the life cycle of a product. The LCA of a product is a methodology that attempts to identify, quantify and characterize the different potential environmental impacts associated with each of the stages of the life cycle of the product [1].

Environmental impact within one of the most important resources we have to take care is water. Water is necessary for life, but the same exploitation and irrational use have been gradually depleting the resource, but not before mentioning that have also contaminated some water supplies, and during the last fifteen years, the green chemistry has become little by little for the culture and methodology to achieve sustainability. Green chemistry is not a new branch of chemistry, but a strategy to carry out the chemistry and engineering in a sustainable way [2].

To be able to define green chemistry, it is necessary to first define sustainable development, since it is the sought after goal. In 1987, the "United Nations Commissions on Environment and Development" present "sustainable development as the satisfaction of the needs in the present without compromising the ability of future generations to meet their own needs".

Green chemistry was subsequently defined, "Design, development and implementation of chemical products or processes to reduce or eliminate the use and generation of hazardous substances" [3].

Agriculture is a way of surviving humans long ago. He has been maturing simple crop to sophisticated practices. Collectively, this complex situation results in the dilemma of sustainable agriculture today.

Currently, we expect a high quality in all products for human consumption, and agriculture is not exempt from this. The protection of the soil is essential to maintain a potential production and ensure a high quality in the products. Agricultural activities not only affect the soil and the agro-ecosystem, protection of other biospheres, the atmosphere and the groundwater has to consider. Nowadays, natural resources are preserved and do not affect the quality of the products obtained, but various factors and procedures can affect the quality.

Pest management techniques have been important in the past fifty years. Synthetic organic chemicals replaced 
inorganic chemical pesticides, and bio-pesticides now constitute a significant part in pest control.

Conventional chemicals will continue to be important components of pest control, and combinatorial chemistry processes and bioassays of high performance will allow the rapid synthesis and testing of many compounds. New and important tools for the control of pests, with microbial pesticides and GM crops play an important role in agriculture.

Herbs are known to cause huge losses in agriculture, due to the interference in agro-ecosystems. Due to concern for the environment and human health, global efforts been made to reduce the heavy reliance on synthetic herbicides that are used for the control of these herbs [4].

Agriculture is one of the biggest consumer activities worldwide. In Mexico, $77 \%$ of water is used in agriculture; $14 \%$ in public water supply; $5 \%$ by thermoelectric and $4 \%$, in the industry.

In Morelos, the production of ornamental plants is of paramount importance, being one of the largest producers nationwide. Production of Impatiens New Guinea ranks third in sales of ornamental plants in the State of Morelos. Due to the large amount of water used for irrigation of Impatiens New Guinea in the state, have a daily watering, it was considered to use hydroponics to produce them using potassium polyacrylate as part of the substrate to lengthen the watering interval.

Hydroponics uses some kind of substrate such as sand, gravel, stone, pumice, aserrines, expansive clays, coals, husks of rice, etc. To which added a nutrient solution containing all the essentials necessary for normal growth and development of the plant [5].

\section{Materials and Methods}

16 Impatiens New Guinea (Bright White) were planted, using cuttings of about 5 centimeters tall. It was used a greenhouse with plastic and mesh shade cover $50 \%$, in raised beds , located at an altitude of $1871 \mathrm{~m}$. The climate of the region is warm with an average annual temperature between $18^{\circ} \mathrm{C}$ and $22^{\circ} \mathrm{C}$. The experiment conducted for 84 days varying the irrigation interval and concentration of nutrient solution. The substrate was prepared using potassium polyacrylate $20 \mathrm{~g} / \mathrm{l}$ mixed with the substrate (coconut fiber $60 \%$, tepojal $20 \%$, ground sheet $20 \%, \mathrm{v} / \mathrm{v} / \mathrm{v})$, the nutrient solution was Steiner solution (Table 1 ) with different concentrations $(40 \%, 60 \%$, $80 \%, 100 \%) 400 \mathrm{ml}$ per plant, with different watering intervals (3, 6, 8, 10 days).

After 84 days of irrigation, each plant separately dried in an oven at $72^{\circ} \mathrm{C}$ for 72 hours. Subsequently, they weighed on an analytical balance.

Values as used nutrient solution and water during the experiment introduced in SimaPro software (Table 2). Eco-Indicator 99 selected this experiment to measure the environmental impact generated per each plant.

\section{Results and Discussion}

Before you begin to format your paper, first write and save the content as a separate text file. Keep your text and SimaPro software raised the data into three categories Human health, Ecosystem quality and Resources, the sum of these three resulted in the environmental impact generated by the process (Table 3).

Table 1. Fertilizers and amounts used according to the percentage of concentration of the nutrient Steiner universal solution.

\begin{tabular}{ccccc}
\hline \multirow{2}{*}{ Fertilizer } & \multicolumn{3}{c}{ Fertilizer Concentration of the complete nutrient solution } \\
\cline { 2 - 4 } & 100 & 80 & 60 & 40 \\
Calciumnitrate & 1.08 & -0.87 & 0.65 & 0.43 \\
Potassiumnitrate & 0.31 & 0.25 & 0.19 & 0.12 \\
Potassium sulfate & 0.27 & 0.21 & 0.16 & 0.11 \\
Magnesium sulfate & 0.50 & 0.40 & 0.30 & 0.20 \\
Potassiumphosphate & 0.14 & 0.11 & 0.08 & 0.06 \\
Ironchelate & 0.04 & 0.04 & 0.04 & 0.04 \\
Micronutrients $^{\mathrm{b}}$ & $1 \mathrm{ml}$ & $1 \mathrm{ml}$ & $1 \mathrm{ml}$ & $1 \mathrm{ml}$
\end{tabular}

${ }^{\mathrm{a}}$ The iron source was Fe-EDTA at a concentration of $13.2 \%$. ${ }^{\mathrm{b}}$ The micronutrient stock solution was prepared with (in g. $1^{-1}$ ): boric acid, 2.88 ; manganese chloride tetrahydrate, 1.81; zinc sulfate heptahydrate, 0.22 ; copper sulfate pentahydrate, 0.18 ; molibdene acid hydrate, 0.02 . 
Table 2. Values used on SimaPro software bringing the WDMs (weight of total dry matter) kg and using the total volume of water used per plant at different concentrations of Steiner solution.

\begin{tabular}{cccccc}
\hline SN \% & WI (days) & TS(l) (84 days) & WDM (g) & WDM (Kg) & TS (l/Kg) \\
\hline 40 & 3 & 11.2 & 2.05 & 1 & 5463.41 \\
& 6 & 5.6 & 1.87 & 1 & 2994.65 \\
& 8 & 4.2 & 1.33 & 1 & 3157.89 \\
60 & 10 & 3.36 & 1.22 & 1 & 2754.10 \\
& 3 & 11.2 & 1.39 & 1 & 8057.55 \\
& 6 & 5.6 & 2.08 & 1 & 2692.31 \\
& 8 & 4.2 & 1.62 & 1 & 2592.59 \\
80 & 10 & 1.36 & 1.73 & 1 & 1942.20 \\
& 3 & 5.6 & 1.46 & 1 & 4671.23 \\
& 6 & 4.2 & 1.40 & 1 & 3075.00 \\
& 8 & 3.36 & 1.33 & 1 & 2526.32 \\
& 10 & 11.2 & 1.02 & 1 & $10,980.39$ \\
& 3 & 5.6 & 1.84 & 1 & 3043.48 \\
& 6 & 4.2 & 1.43 & 1 & 2937.06 \\
\end{tabular}

SN-Steiner solution concentration, WI-watering interval, TS-total solution used during the experiment, WDM weight of dried matter. The WDMs plant measured with an analytical balance after leading oven at $72^{\circ} \mathrm{C}$ each floor. An adjustment $1 \mathrm{Kg}$ WDMs performed and thus the volume of nutrient solution was used.

Table 3. Results of environmental impact (points), the use of potassium polyacrylate as part of the hydroponic substrate in Impatiens New Guinea using SimaPro software, compared with the Eco Indicator 99.

\begin{tabular}{cccccc}
\hline Damage category & Unit & SN-40WI-3 & SN-40 WI-6 & SN-40 WI-8 & SN-40 WI-10 \\
\hline Total & Pt & 1.0980 & 0.6019 & 0.6347 & 0.5535 \\
Human health & Pt & 0.6810 & 0.3733 & 0.3936 & 0.3433 \\
Ecosystem quality & Pt & 0.0208 & 0.0114 & 0.0120 & 0.0105 \\
Resources & Pt & 0.3961 & 0.2171 & 0.2290 & 0.1997 \\
Damage category & Unit & SN-60 WI-3 & SN-60 WI-6 & SN-60 WI-8 & SN-60 WI-10 \\
Total & Pt & 2.1886 & 0.7311 & 0.7042 & 0.5274 \\
Human health & Pt & 1.3867 & 0.4632 & 0.4462 & 0.3342 \\
Ecosystem quality & Pt & 0.0366 & 0.0122 & 0.0118 & 0.0088 \\
Resources & Pt & 0.7652 & 0.2556 & 0.2462 & 0.1844 \\
Damagecategory & Unit & SN-80 WI-3 & SN-80 WI-6 & SN-80 WI-8 & SN-80 WI-10 \\
Total & Pt & 2.6432 & 1.5075 & 1.0337 & 0.7793 \\
Human health & Pt & 1.6989 & 0.9689 & 0.6644 & 0.5173 \\
Ecosystem quality & Pt & 0.0431 & 0.0245 & 0.0168 & 0.0102 \\
Resources & Pt & 0.9011 & 0.5139 & 0.3524 & 0.2517 \\
Damagecategory & Unit & SN-100 WI-3 & SN-100 WI-6 & SN-100 WI-8 & SN-100 WI-10 \\
Total & Pt & 4.5736 & 1.2675 & 1.2233 & 0.9147 \\
Human health & Pt & 2.9743 & 0.8243 & 0.7955 & 0.5948 \\
Ecosystem quality & Pt & 0.0638 & 0.0176 & 0.0170 & 0.0127 \\
Resources & Pt & 1.5354 & 0.4255 & 0.4107 & 0.3070
\end{tabular}

The sum of the 3 categories gives the environmental impact (points), comparison made with the Eco-Indicator 99. SN—Steiner solution concentration \%, WI-watering interval (days).

The lowest environmental impact showed in Table 3 was with a 60\% Steiner solution concentration and an interval of 10 days of irrigation with a value of 0.5274 points. In Figure 1, comparison of each treatment was best seen. Concentrations of $40 \%$ and $60 \%$ showed the lowest values, so concentrations of $80 \%$ and $100 \%$ of 


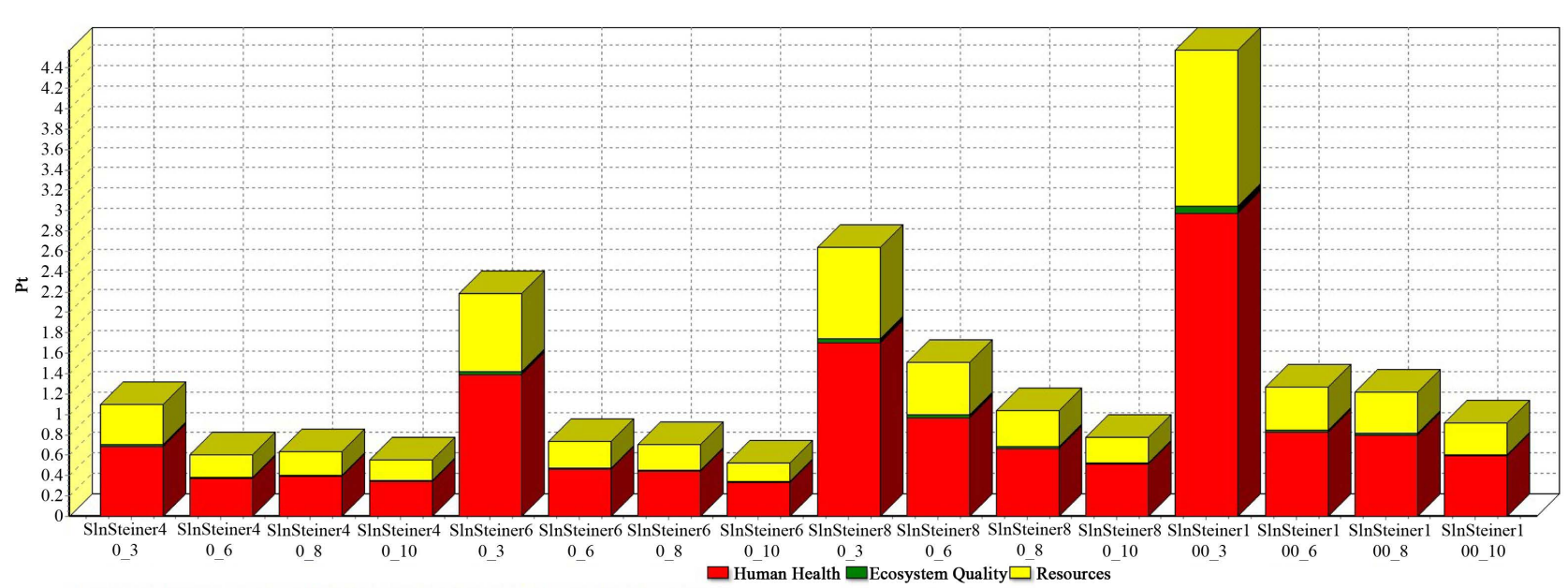

Comparando fases del producto; Método: Eco-indicator $99(\mathrm{H})$ V2.09 / Europe EI 99 H/A / Puntuación única / Excluyendo procesos de infrastructura / Excluyendo emisiones a largo plazo

Figure 1. Comparison of different concentrations of the Steiner solution with different watering intervals using potassium polyacrylate in the production of Impatiens New Guinea. Method Eco-indicator 99 (H) V2.09/Europe EI99 H/A, only punctuation.

Steiner solution is saturated, and they made a bigger environmental impact. The figure also showed that the lower the watering interval is greater damage.

\section{Conclusions}

The use of potassium polyacrylate as part of the substrate in hydroponics helped to lengthen the interval thanks to the irrigation water absorption of the polymer, resulting in a savings of water and nutrient solution, reduced environmental impact generated in soil and water. Impatiens New Guinea (Bright White) were obtained with the required quality of ornamental plants watering for 84 days, using different concentrations of Steiner solution, and using potassium polyacrylate as part of the hydroponic substrate to raise nutrition of plant and extend the watering interval. The best results were obtained using the concentrations of $40 \%$ and $60 \%$ Steiner solutions.

SimaPro software measured the environmental impact of the use of the polymer varying hydroponics irrigation interval and concentration of the Steiner solution. In the software data as Steiner concentration, the volume of water used during the experiment in 84 days and the weight of dry matter introduced, resulting in the least environmental impact generated with a $60 \%$ Steiner concentration and irrigation interval of 10 days. It shows that Steiner solutions of $80 \%$ to $100 \%$ at concentrations saturated generate a greater environmental impact. The concentration of $60 \%$ of Steiner solution is totally recommended in the Impatiens New Guinea production, watering should be monitored because of the possible water stress in plants.

\section{References}

[1] Rodríguez, B.R. (2003) El análisis del ciclo de vida y la gestión ambiental. Boletinii E, 91-97.

[2] Lancaster, M. (2010) Green Chemistry: An Introductory Text. Royal Society of Chemistry.

[3] Anastas, P.T. and Warner, J.C. (1998) Química Verde: Teoría y práctica. Prensa de la Universidad de Oxford, 11.

[4] Nelson, W.M. (2004) Agricultural Applications in Green Chemistry. In: ACS Symposium Series, Vol. 887, American Chemical Society, 3-6. http://dx.doi.org/10.1021/bk-2004-0887.ch001

[5] Van Os, E.A. (1994) Ingeniería y aspectos ambientales de los sistemas de cultivo sin suelo. Hidroponía y Trasplante de producción, 396, 25-32. 